\section{References}

Mathews, David. 1991. "After Thoughts." Kettering Review, Fall 1991: 78.

Polsby, Nelson W. 1984. Political Innovation in America: The Politics of Policy Initiation. New Haven: Yale University Press.

Polsby, Nelson W. 1969. "Political Science and the Press: Notes on Coverage of a Public Opinion Survey on the Vietnam War." Western Political Quarterly 22 (March): 47-60.
Polsby, Nelson W. 1960. "Towards an Explanation of McCarthyism." Political Studies 8 (October): 250-71.

Stouffer, Samuel. 1955. Communism, Conformity and Civil Liberties. New York: Doubleday.

U.S. Department of Labor. 1965. The Negro Family, The Case for National Action. Washington, DC: U.S. Government Printing Office.

Verba, Sidney, Richard A. Brody, Edwin B. Parker, Norman H. Nie, Nelson W. Polsby, Paul Ekman, and Gordon S. Black. 1967. "Public Opinion and the
War in Vietnam." American Political

Science Review 61 (June): 317-33.

\begin{abstract}
About the Author
Nelson W. Polsby is a professor, department of political science, and director of the Institute of Governmental Studies, University of California, Berkeley.
\end{abstract}

\title{
Tips for Writing Papers
}

\author{
Raymond E. Wolfinger, University of California, Berkeley
}

Every year I read graduate students' papers, many of which are very good. (Some of these, fewer than I would like, are submitted to journals and published.) Whether good, bad, or indifferent, the papers often have certain weaknesses. After 30 years of exhorting students about these failings, I realized that I could save a lot of time by writing down my collected maxims. And nearly 30 years of refereeing manuscripts convinces me that these suggestions are equally appropriate for journal articles and books.

If your paper requires any sort of data gathering-interviewing politicians or ordinary citizens, observing public meetings, scrutiny of documents, analysis of the mass media, whatever-make a start on this as soon as you possibly can, before getting everything just right and doing all necessary reading. At the very least, you will learn if your plans are feasible. You may also achieve a better understanding of your topic that will alter your reading plans or, perhaps, the focus of your research.

Before you begin writing, figure out what your contribution to knowledge is going to be and organize the paper accordingly. This does not mean that you must present a lengthy survey of the literature. It does mean that some place near the beginning of the paper you should say enough about the existing state of knowledge to establish the context for your own contribution and help readers understand what you will tell them that they did not know before.

Then you should say what the paper will be about, including what specific topics you are going to explore. Perhaps also you should disclose your principal conclusions. The point is that you should never leave readers confused or uncertain about where you are going next or why you are saying what you are saying. Throughout the paper there should be a clear story line to make it easy for readers to follow you from point to point.

One implication of the preceding two paragraphs is that the introductory section or chapter probably should be written last. It's always easier to introduce something when you have the clearest idea what that something is.

Some sections of a paper are easier to write than others. Unless there is a good reason not to, I recommend starting with the easy parts. This will get the show on the road, always an important consideration when there is a risk of writer's block. (And who among us does not suffer from this ailment at least some of the time?) It will also build your confidence about the value of what you have found.

When dealing with topics that touch on the controversial, in either the scholarly or political sense, always ask yourself if it is necessary to engage in the controversy. If the controversy is essential to what you want to say, then plunge in. Your contribution will be clear, and the experience can be satisfying if not downright enjoyable. But if you can make your point without starting a fight, by all means do so. The reason is simple: You should avoid distracting readers or antagonizing them unnecessarily; you are likely to get greater acceptance from people with whom you have not picked a fight.

\section{Papers with Quantitative Data}

Begin some part of the data analysis at your earliest convenience, if possible, before doing all the background reading. This is less essential if you know for a fact that the data set you want is immediately available in the form in which you will analyze it, that you know how to do that analysis, and that you will not make any mistakes in preliminary steps like coding or recoding the data to fit your analysis plans. Nothing is more damaging to inner peace and efficient scholarship than a nasty surprise about any of these points three weeks before the end of the semester.

When beginning to analyze your data, you will note how many cases you have. Doubtless many of your data runs will be based on fewer cases for various good reasons; perhaps respondents who failed to answer or had no opinion. But be sure you know where all your cases are. Whenever you have less than the number of cases you started with, be able to account for the missing ones. If you think this advice is unneces- 
sary or simple-minded, good luck to you.

You should not organize your paper autobiographically; that is, do not write a narrative of "first I did this and then I did that." Do not plod through tables one after the other without a plan. What you did in the course of analyzing data for the paper need not be recapitulated in the course of presenting your findings. Remember, your goal should be to write the clearest and most persuasive account of your conclusions, not take readers up and down all the byways you followed to get there.

This does not mean, however, that you should fail to describe how you eventually chose to organize your data, what criteria you used to assign cases to categories, and so on. Far from it. Anyone reading your work should be able to replicate it without having to ask you how you did it. The challenge of describing your data analysis choices may help you to a stronger and more explicit rational structure for your argument (what some scholars might call "specifying your model'').

When you are in this preliminary phase of deciding on operational definitions, you may encounter hard choices about what cases go in what categories, what should be excluded from analysis, and the like. What about respondents without an opinion or legislators who abstained from voting? Should all white collar employees be considered middle class, or is it better to subdivide them into upper and lower middle class? When does old age begin? One approach is to agonize about every decision and then defend your choice. The preferable alternative is to do it both ways to see what difference it makes. The cost in effort and computer time will be negligible, and the payoff might be considerable. At least, you can assure readers in a footnote that different procedures yielded the same result. On the other hand, if the result is different, this may give you an idea for further analysis.

It is usually a good idea to convey some sense of the magnitudes and distributions of your key variables before proceeding, if necessary, to higher levels of analysis. Marginals and cross tabulations may be humble fare, but at the least they orient readers to the phenomena you will be exploring, and often they will suffice to establish much of what you want to get across.

The tables that you used in the course of doing your research are not necessarily (indeed, very rarely) what you present. A table or graph of any kind is an aid to communication, a supplement to what you say in sentences and paragraphs. On the one hand, any table you use should be self-explanatory; any footnotes that are required to understand the table should appear with it. On the other hand, you should write the text of the paper, to the extent possible, as if you could not include any tables. You should use tables for data that cannot be adequately presented in the text. Occasionally, a table might be a useful means of summarizing data.

Because tables should be written for the purpose of communicating, they should not be xeroxed printouts. Nor should you present a table with hundreds of cells, because no one can possibly understand so many facts. You should analyze the data thoroughly and then present in tabular form those particular things that help your reader understand what you have found.

Another implication of this injunction is that a great deal of the data that you analyze in the text need not be in a table that you also present. Many important findings can be presented verbally and do not require any kind of tabular material. Including a table in a paper does not relieve you of the obligation to describe specifically what is in that table. You should not solve the problem of data description by instructing readers to look at Table 2 if they want to know what you found. (This might be called the pearls before swine approach.) Moreover, you may find that further ideas will occur to you as you interpret tables in writing. Nelson Polsby makes the point nicely: "I think by writing."

Tables should be aids to clear communication; you may consider them archives, but they should not play this role in the paper itself. This means, among other things, that the table should appear as close as possible to its major use in the paper. Appendices should be reserved for complicated material that is not necessary to understand what you are saying and is included to help specialists understand the details of your procedures. The appendix is not an aid to communication; it is a supplementary and often unnecessary part of the paper in which you put technical material.

If you are doing any sort of multivariate analysis, do not limit your description of the results to a vague adjectival formulation like, "As Regression II shows, education is less important than political interest." The whole point of multivariate analysis is to be able to describe precisely relationships among variables. And while we're talking about multivariate analysis, you will be much more persuasive if you can tell the reader how much change in the dependent variable will be produced by such-and-such a change in the independent variables of interest.

Two minor points: it is seldom necessary, either in the text or in tables, to use a decimal point when you are giving percentages. The difference between $32.2 \%$ and $32.7 \%$ is neither statistically nor substantively significant. The extra digit conveys no useful precision and is a distraction to anybody who wants to understand what you are saying. Second, when you have a truly dichotomous dependent variable, like votes in a legislature, where the two possible values add up to $100 \%$, just give one or the other value. This will cut down on the size of tables and make it easier for your readers to see comparisons.

\section{About the Author}

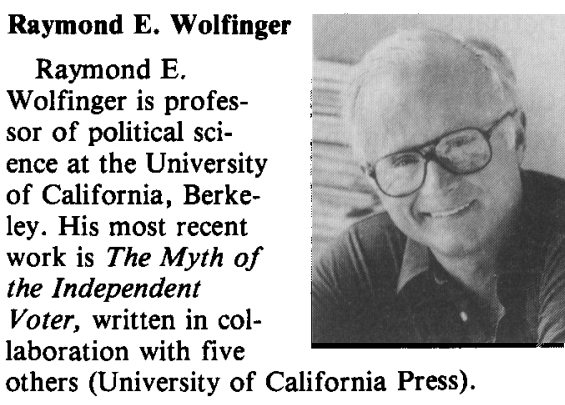

